\title{
On Diagnostics of Military Fortification Constructions
}

\author{
Eva ZEZULOVÁ ${ }^{1}$, Lubomír KROUPA ${ }^{2}$
}

\begin{abstract}
${ }^{1}$ Department of Engineer Technology, Faculty of Military Technology, University of Defence in Brno, Address: Kounicova 65, 66210 Brno, Czech Republic

${ }^{2}$ Department of Engineer Support, Faculty of Military Leadership, University of Defence in Brno, Address: Kounicova 65, 66210 Brno, Czech Republic
\end{abstract}

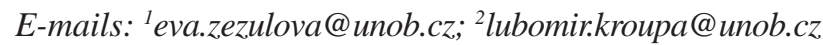

\begin{abstract}
The article deals with military fortification constructions, their evaluation and field experimentation. Furthermore, it discusses legal standards, international and national regulations that set parameters and effects on military fortification structures. The diagnosis of structures can be characterized as a statement of differences between the assumed (projected) state and the current state of the examined structure. While field experimentation is an effect on structures and monitoring behavior and changes in the state of the structure. Considering the specific accidental actions, it is necessary to use diagnostic procedures other than conventional constructions, especially regarding the impossibility of breaking the structure by removing the specimen. It is necessary to evaluate the structure for a different type of action than usual. Some field tests were conducted at the Department of Engineer Technology according to STANG 2280. Some, however, were carried out according to their own procedure. These activities are referred to in the paper as field experiments and were used mainly to verify mathematical simulations of the behavior of actioned structures, and to make the experiments of field experiments more precise.
\end{abstract}

KEY WORDS: military fortification construction; Non-destructive testing (NDT) methods; Ultra High-Performance Fibre Reinforced Concrete (UHPFRC); Ultrasonic Pulse Velocity (UPV) testing method

\section{Introduction}

The lethality of modern weapons systems makes the area of military operations an increasingly hostile environment. One of the most important tasks for all military operations is survivability that includes all aspects of physically protecting personnel, weapons, and materiel from the effects of enemy weapons regardless of threats category. An enemy may use massive offensive air support, aviation and direct/indirect fires within a conventional encounter or wide range of capabilities from Improvised Explosive Devices (IEDs) to modern anti-armor weapons and mortars or rockets in asymmetric warfare.

A similar situation can be detected in connection with threats of terrorist attacks on civilian installations. Any raid to such targets can be conducted by explosive means (IEDs) that expose the construction and specific elements of the construction to extreme actions as dynamic overpressure or penetration by fragments. The changes of global security and rising possibility of a raid on critical infrastructure or other civilian targets leads to changes in the approach to the design and dimensioning of critical infrastructure elements and structures on national and cross-border level. The approach to designing modern civilian public or critical infrastructure facilities is to mitigate potential risks of any raid, primarily attacks associated with application of explosive means. Preventive protective and safety measures are based on the entry-exit modes, security technologies (cameras, scanners) and the installation of restraint systems [1].

As a follow-up to mentioned changes new diagnostic techniques used to check status of the existing structures that had been subjected to extreme actions have to be developed and verified [2, 3]. Either construction or constructional elements have been hit by the blast effects (pressure wave or fragments) should be assessed for their further reliable and safe employment. Objective assessment can prevent further damage or can prevent or mitigate impacts of the ride, e.g. an attack on road transport infrastructure with supposed damage of some transport construction can be the cause of societal risks [4].

The identical problem must be solved in the military fortification constructions field. The need to protect the force from a range of possible threats is permanent and responsibility for survivability depends on the level of protection required. Basic survivability is an all arms/branches obligation, survivability measures on this level

${ }^{1}$ Corresponding author. Tel.: 00420-973-443-250.

E-mail address: eva.zezulova@unob.cz 
begin with the use of all available concealment and cover, followed by digging and constructing field fortifications, mainly fighting and protection positions. Engineers provide support to the basic measures by advice and assistance as they have knowledge, skills and competences. In case of short time, hard soil or considerable quantity of protective measures engineers may provide support to unit survivability measures by provision of specialist skills, equipment, explosive means and either protective structures or protective barriers.

Military fortifications have a long history, but the principal construction materials remain the same - timber, rocks and earth. From the beginning of the 20th century, these materials were supplemented with concrete and steel, but conception of field fortifications stayed the same - they were built within preparations for fight or during fight and they were in use as long as the troops remained in their positions (areas) whereupon the fortifications were either abandoned or destroyed. The situation changed with the emergence of nuclear weapons when rose the development of commercially produced prefabricated and easily transportable field fortification constructions.

The same situation happens once again in relation to expeditionary style of military operations that can be conducted around the world. This style of operations entailed the requirement for effective temporary structures and installations including field fortifications along with taken advantage of new materials as High Performance Concretes (HPC), Ultra-High-Performance Concrete (UHPC) [5] or High-Performance Fibre Reinforcement Concrete (HPFRC) and others.

Concerning military fortification is necessary to mention difference between terms "protective structure" and "field fortification". In general, a protective structure is any structure that could protect against diverse effects of weapons (whether conventional or mass destruction) and provides protection against vagaries of the weather. Protective structures can be constructed for the different purposes, with application of wide range of materials and as temporary or permanent. Temporary military protective structures have been usually constructed as field fortification, whereas permanent ones have been designed primarily to protect command posts (CP), communication centers, arms depots and things like that. Depending on the territory, permanent protective structures are mostly predestined to protect the population and to ensure the readiness of civil protection resources during an armed conflict, particularly in case weapons of mass destruction (WMD) have be used. They provide a basic form of protection against a wide range of direct and indirect arms impact and they should also be available in case of disasters and emergencies.

Field fortifications pose military protective structures predestined to protect forces against the consequences of direct and indirect fire. Field fortification presents an emplacements or shelters of a temporary nature that can be constructed with reasonable facility by units requiring no more than minor engineer supervisory and equipment participation [6]. Emplacements or shelters present military protective structures constructed traditionally in most cases within warfighting operations but reflecting the changed operational environment more effective and transportable protective structures in order to better protect the Force from a wide range of threats are needed [3].

There is set both general and specific requirements that transportable protective structures have to meet:

- Aboveground built.

- Transportable forward to the operational site by tactical means of transport.

- Simple assembly on site.

- Prefabricated as possible or set up by local materials.

- Resistance to penetration by projectiles or weapon casing fragments.

- Resistance to blast at close proximity.

- Reusability.

As additional requirement can be protection against incendiaries and CBRN contamination.

To meet major part of the requirements is task for materials research [5], logistics, tactics as well as engineers. On the contrary, reusability and verification of protective characteristics, especially after exposure to hit or blast posed a problem. Structures that have been hit by the blast effects (pressure wave, projectile or fragments) should be assessed for their further use $[5,7,8,9]$. It is therefore necessary to assess whether the fortification structure is capable of withstanding additional actions, or it has already lost its protective function and it can no longer be used for forces protection.

One of the options is application of test procedures set down in NATO standard [6] that is intended for engineers and aimed to provide a common understanding of the protection offered by protective structures against specific threats. However, stated test procedures are destructive, which excludes reusability and verification of protective characteristics of tested structures.

This standard enables common understanding of threat assessments and weapons effects by setting groups of representative weapons classified by category and severity of effect, as shown in Table 1 (only extract from the standard).

Some field tests were conducted at the Department of Engineer Technology according to STANG 2280 [7]. Some, however, were carried out according to their own procedure. These activities are referred to in the paper as field experiments and were used mainly to verify mathematical simulations of the behavior of actioned structures, and to make the procedures of field experiments more precise. 
The diagnostics of structures can be characterized as a statement of differences between the assumed (projected) state and the current state of the examined structure. While field experimentation is an effect on structures and monitoring behavior and changes in the state of the structure.

Considering the specific accidental actions, it is necessary to use diagnostic procedures other than conventional constructions, especially regarding the impossibility of breaking the structure by removing the specimen. It is necessary to evaluate the structure for a different type of action than usual.

Table 1.

Selected weapon categories and severity of effect [6]

\begin{tabular}{|c|c|c|c|c|c|}
\hline & \multicolumn{4}{|c|}{ Weapon category } \\
\hline & & A & B & $\mathrm{C}$ & D \\
\hline & & Projectiles & $\begin{array}{l}\text { Direct Fire } \\
\text { Warheads }\end{array}$ & $\begin{array}{l}\text { Indirect Fire } \\
\text { Munitions }\end{array}$ & $\begin{array}{l}\text { High Explosives } \\
\text { (TNT E }{ }_{\text {avt }} \text { ) }\end{array}$ \\
\hline \multirow{4}{*}{ 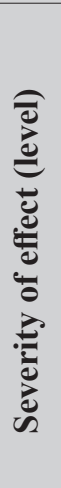 } & 4 & $\begin{array}{c}\text { HMG } \\
12.7 \mathrm{~mm}(0.50)\end{array}$ & $\begin{array}{c}\text { Anti-personnel thermobaric } \\
\text { orconventional charge } \\
<2.5 \mathrm{~kg}\end{array}$ & $\begin{array}{l}120 \mathrm{~mm} \text { mortar } \\
107 \mathrm{~mm} \text { rocket }\end{array}$ & $\leq 2.0 \mathrm{~kg}$ \\
\hline & 3 & $\begin{array}{l}\text { Assault / sniper } \\
\text { Rifle } \\
7.62 \mathrm{~mm} \mathrm{AP}\end{array}$ & $\begin{array}{c}\text { Anti-tank } \\
\text { shaped charge }\end{array}$ & $82 \mathrm{~mm}$ mortar & $\leq 1.0 \mathrm{~kg}$ \\
\hline & 2 & $\begin{array}{c}\text { Assault rifle } \\
5.56-7.62 \mathrm{~mm} \text { ball }\end{array}$ & $\begin{array}{l}40 \mathrm{~mm} \text { rifle grenade } \\
\text { shaped charge }\end{array}$ & $60 \mathrm{~mm}$ mortar & $\leq 0.5 \mathrm{~kg}$ \\
\hline & 1 & Pistol & (reserved) & Hand grenade & $\leq 0.1 \mathrm{~kg}$ \\
\hline
\end{tabular}

\section{Field Experimentation Lessons Learned}

The beginnings of practical field testing at the Department of Engineer Technology date back to 2004. In most cases, cement-based materials have been tested. The first field experiments were conducted under the leadership of our colleague Jiři Štoller. The results of the tests were incorporated into his dissertation entitled "The Use of the Reinforced Concrete for Protective Structures"[8].

On the other field experiments, again under the direction of the our colleague Stoller, our Department of Engineer Technology was cooperating with the Czech Technical University in Prague and the Military Research Institute in Brno. The charges, setting up and ignition were provided by the 15th Engineer Brigade.

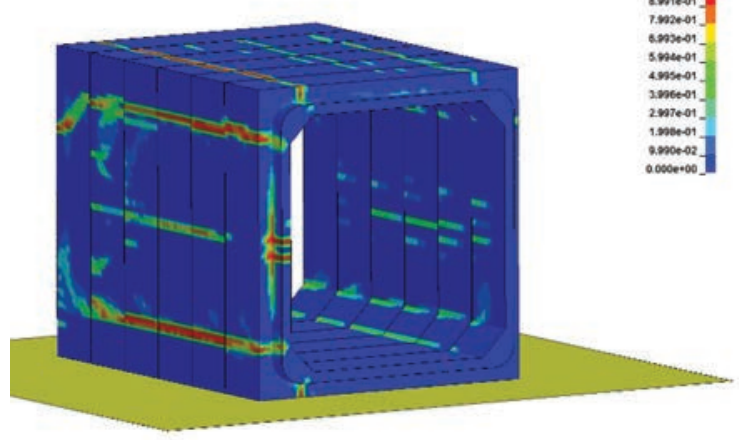

Fig. 1. Numerical simulation of the protective structures loaded by the explosion of the $20 \mathrm{~kg}$ of TNT from 10 meters distance - A view (the view outside the shelter on the loaded wall) [12].

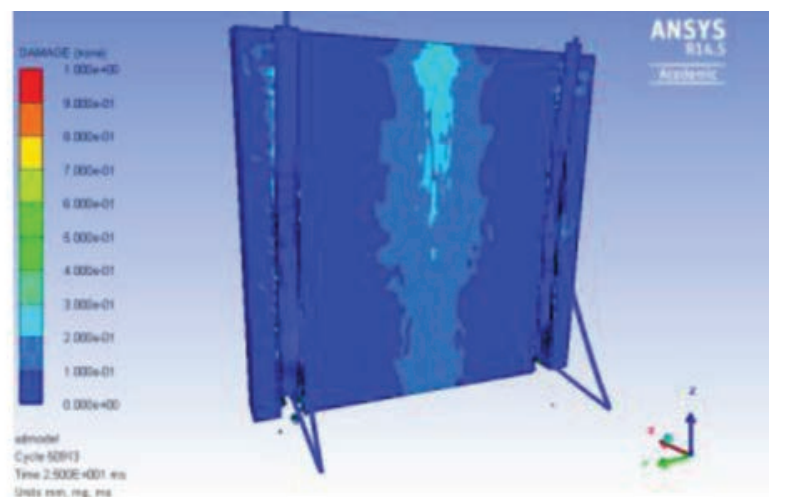

Fig. 2. The mathematical model in ANSYS-AUTODYN software of the tested thick Slab - damage caused by 20 $\mathrm{kg}$ TNT charge $2.0 \mathrm{~m}$ distant [13].

A numerical simulation of the action of the test sample or the structure by explosion was always performed before the field experiment. The simulations were performed in ANSYS-AUTODYN programming environment. The simulations are especially important for the correct design of the experiment where there is no idea of the behavior of the loaded structure. It is also very important, especially because of the estimate locations of structural failure. 
Special consideration shall then be given to places of the expected failure when evaluating the test results after an explosion action. Especially visual inspection of the crack's detection and the comparison of ultrasonic transmission velocities (measurements before and after explosion action) for discontinuities location of the structure. The result of the numerical simulation of the protective structures loaded by the explosion of the $20 \mathrm{~kg}$ of TNT from 10 meters distance, see Fig. 1. On the Fig. 2, there is the mathematical model in ANSYS-AUTODYN software of the tested thick Slab. Its damage was caused by $20 \mathrm{~kg}$ TNT charge. For proper simulation, it is very important that simulations boundary conditions were very similar to the experiment boundary conditions.

On the Fig. 3 there could be seen definition of boundary conditions of the experiment in auxiliary material. When simulating, the plate was firmly fixed to the ground. In the experiment, the entire stand with the slab moved in the direction of the explosion. On Fig 4. there are seeable the consequence of insufficient anchoring of the sample frame to the ground. Due to other boundary conditions, there was a difference between the behavior of the slab during simulation and under the real action in the experiment.

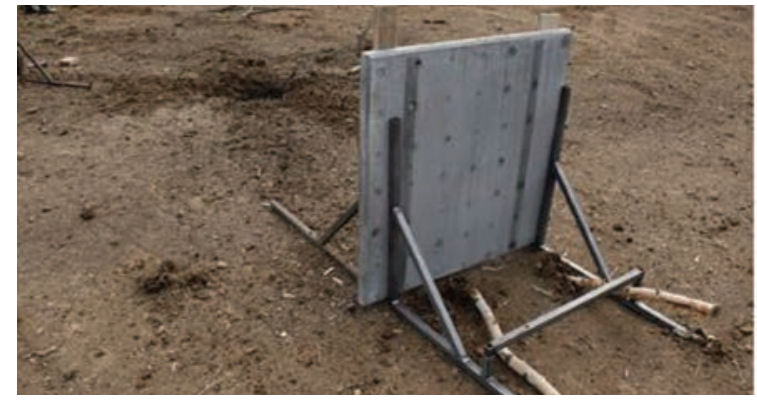

Fig. 3. The definition of boundary conditions of the experiment in auxiliary material [13].

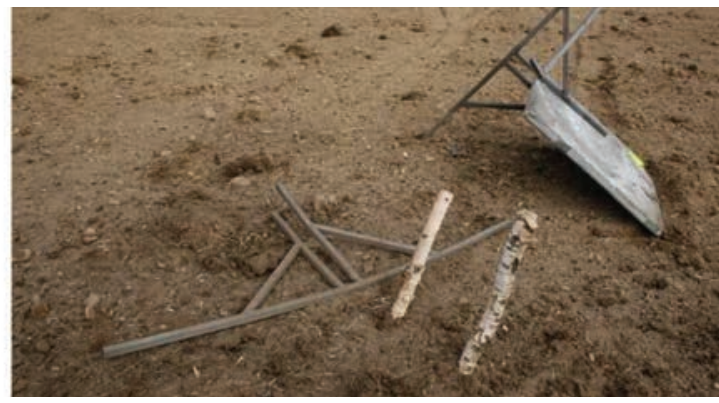

Fig. 4. The consequence of insufficient anchoring of the sample frame to the ground [13].

Over the years, various types of structures have been tested by the Department of Engineer Technology. Different shapes and materials of the tested constructions. In terms of shapes, both frame structures (see Fig. 5) and plate structures (see Fig. 6) were tested. Various modifications of the cementitious materials and multi-layer concrete slabs [18] were tested. For example, the High-Performance Fibre Reinforced Concrete (HPFRC) and also the Ultra High-Performance Fibre Reinforced Concrete (UHPFRC).

In order to verify the material properties of the concrete, test cubes and beams were always produced along with the loaded structures. Test samples were produced and handled in accordance with the Czech Technical Standards ČSN EN 12390-1 [14] and ČSN 12390-2 [15]. For the test of compressive strength were produced cubes with length of the edge $150 \mathrm{~mm}$. For tensile test were produced beams with dimensions 150x150x600 mm.

Individual samples were labelled with the sample number before testing and were marked with points of the measuring network to detect changes in the structure before and after the explosion action. See Fig. 5 and 6.

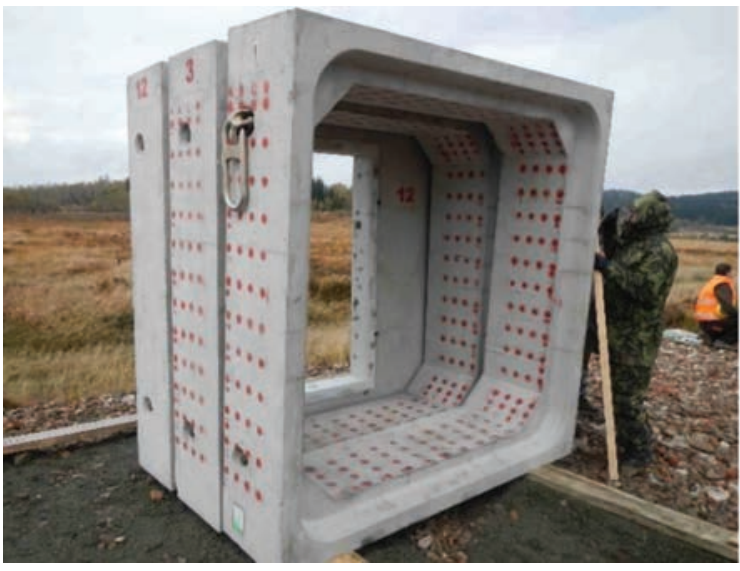

Fig. 5. Frames protective structures provided with measurement points [12].

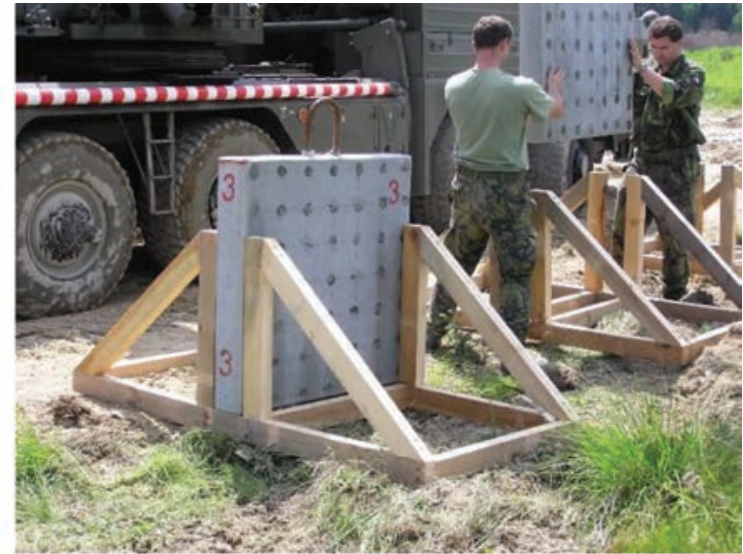

Fig. 6. Test plates inserted into test stands. Marked and provided with measuring points [16].

Unfortunately, sometimes samples were not pre-labelled, and they had to be labelled on site. Especially in the rain, it was extremely demanding to additionally draw a measuring grid on the samples. The soaked concrete could not be sprayed with acrylic spray, see Fig. 7 . The acrylic paint spray did not adhere to wet concrete. Therefore, it was 
sometimes necessary to take a permanent marker, see Fig. 8. It is also important to mark the front and back of the sample. Specification of samples is very important, especially for backward description of the experiment.

After transporting the samples to the test site, they had to be placed in the desired position. The plate samples were placed in the desired position using wooden (see Fig. 6) or steel (see Fig. 9 and 10) racks. Tested slabs were made from various materials based on cement and it had dimensions of $1000 \times 1000 \mathrm{~mm}$, and it has different thicknesses.

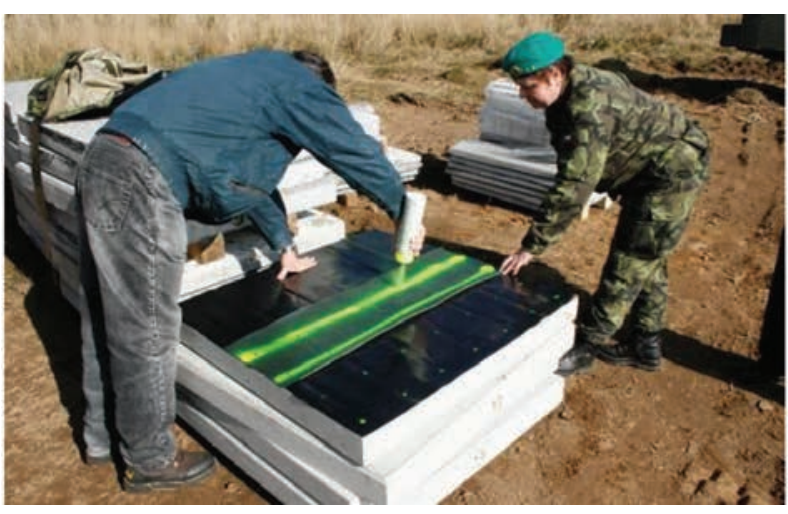

Fig. 7. Additional labelling of test samples with acrylic spray.

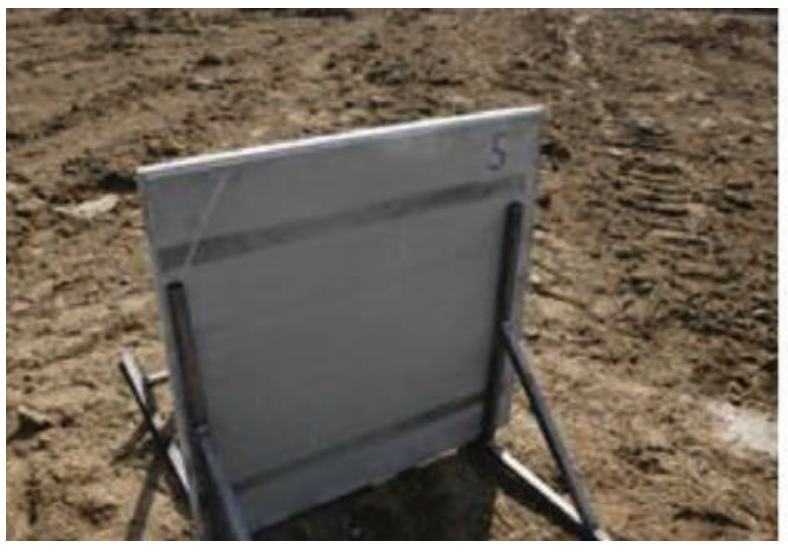

Fig. 9. The test sample before loading by TNT explosion [13].

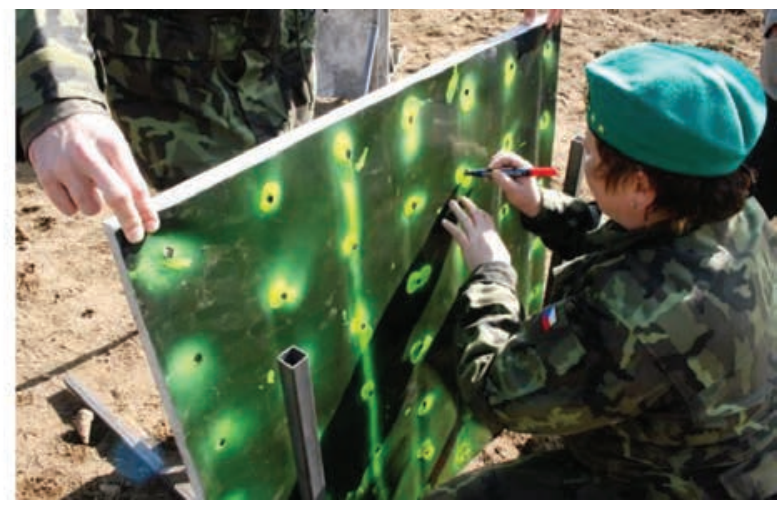

Fig. 8. Additional labelling of test samples with permanent marker.

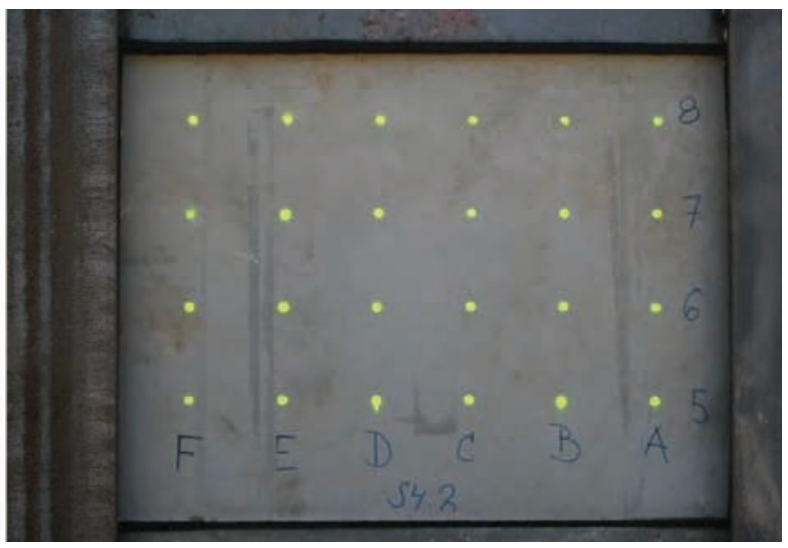

Fig. 10. Construction of the test wall on which the measuring points are marked [8].

For practical tests have been used explosives:

- $\quad$ TNT demolition charges 75, 200 and 400 grams - blocks of pressed TNT wrapped in waxed paper with rectangular body. They were used to form bulk charges for tests. See Fig. 11.

- SEMTEX 10 - plastic explosive of black color based on a non-explosive plasticizer with the active component pentrite. It can be cut with a knife and can be molded to shape by hand and remains plastic from $-30{ }^{\circ} \mathrm{C}$ to $+50{ }^{\circ} \mathrm{C}$. It is unaffected by moisture and is relatively insensitive to shock. It is about $50 \%$ more effective than TNT. See Fig. 12.

- Pl Hx 30 - plastic explosive of light grey color based on a non-explosive plasticizer with the active component pentrite and hexogene supplemented with aluminium powder. It can be cut with a knife and can be moulded to shape by hand and remains plastic from $-40{ }^{\circ} \mathrm{C}$ to $+60{ }^{\circ} \mathrm{C}$. It is unaffected by moisture and is relatively insensitive to shock. It is about $50 \%$ more effective than TNT. See Fig. 13.

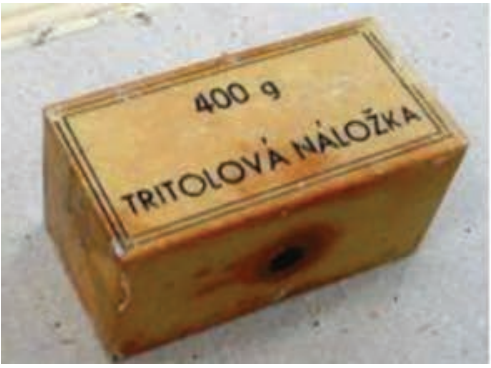

Fig. 11. TNT block 400 g.

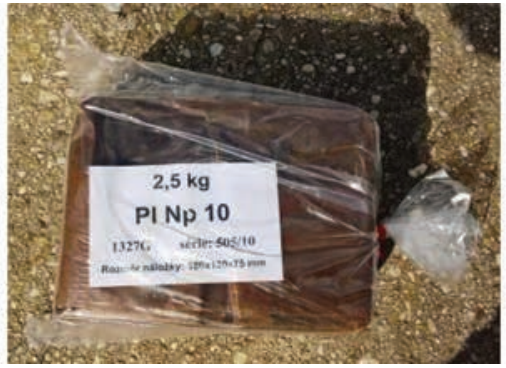

Fig. 12. Semtex 10.

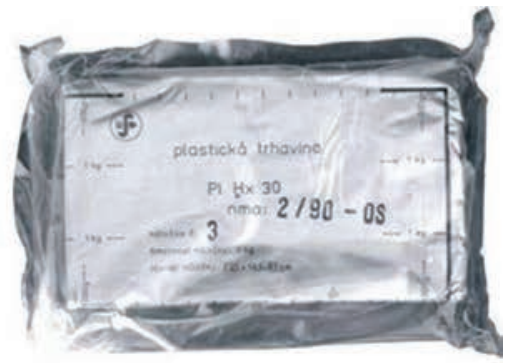

Fig. 13. Pl Hx 30. 
For the used explosives general characteristic see Table 2. Fig. 14 shows a charge of $2000 \mathrm{~g}$, which is located $1 \mathrm{~m}$ from the test object and at a height of $1 \mathrm{~m}$ above the ground. Fig. 15 shows the explosion itself.

After loading, photographic documentation was always taken, or the distance and direction of scattered fragments of the structure were measured. Subsequently, the measuring equipment, sensors and cameras were checked in dependence on the measured parameters. Figures 16 and 17 show ultrasonic verification of cracks in the test plates.

Table 2.

General characteristic of used explosives

\begin{tabular}{|l|c|c|c|c|}
\hline \multicolumn{1}{|c|}{ Characteristic } & Unit & TNT & SEMTEX 10 & PI Hx 30 \\
\hline Explosion heat & {$\left[\mathrm{kJ} \cdot \mathrm{kg}^{-1}\right]$} & 4230 & 5030 & 5740 \\
\hline Detonation velocity & {$\left[{\left.\mathrm{m} . \mathrm{s}^{-1}\right]}^{-3}\right]$} & 6700 & 7600 & 7350 \\
\hline Density & {$\left[\mathrm{kg} \cdot \mathrm{m}^{-3}\right]$} & 1530 & 1510 & 1570 \\
\hline Detonation pressure & {$[\mathrm{GPa}]$} & 16.1 & 17.6 & 20.0 \\
\hline
\end{tabular}

Field experimentation is itself demanding in preparation and execution as it takes place off site and it is necessary to load and bring all equipment to the site of the experiment. Another influence that affects the results and course of field testing is the vagaries of the weather. However, they cannot be influenced. See Fig. 18 and 19.

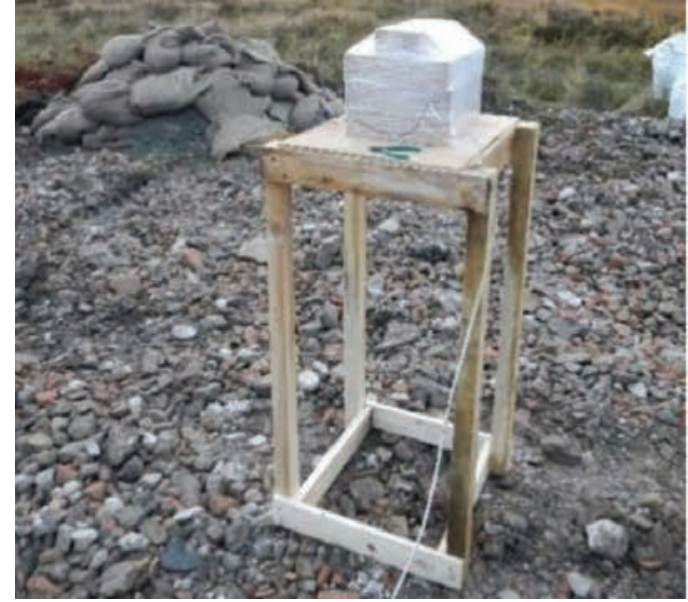

Fig. 14. The charge of $20 \mathrm{~kg}$ of TNT at a height of one meter above the ground [12].

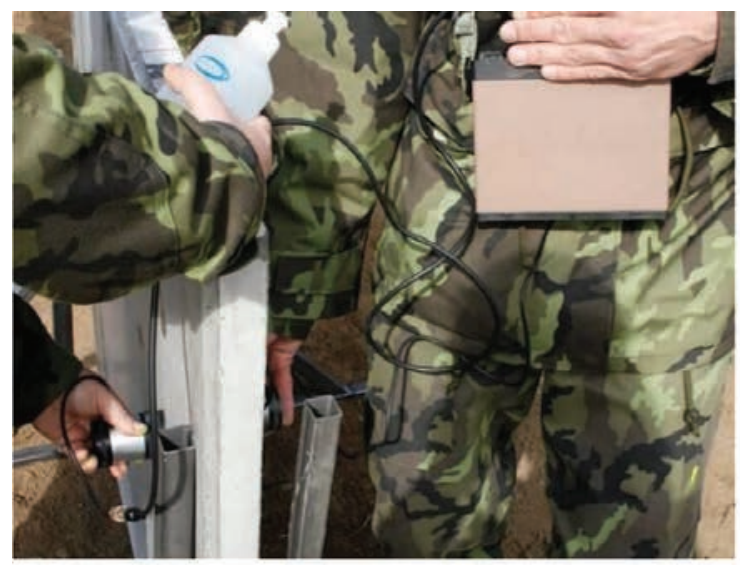

Fig. 16. Ultrasonic verification of cracks in the testing slab made from HPFRC, after loading by TNT explosion [13].

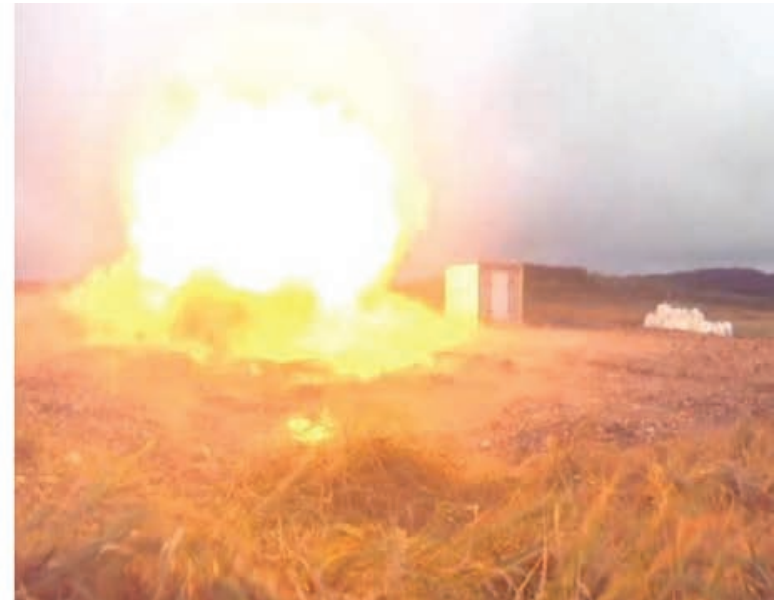

Fig. 15. The protective structure loaded by the explosion of $20 \mathrm{~kg}$ of TNT [12].

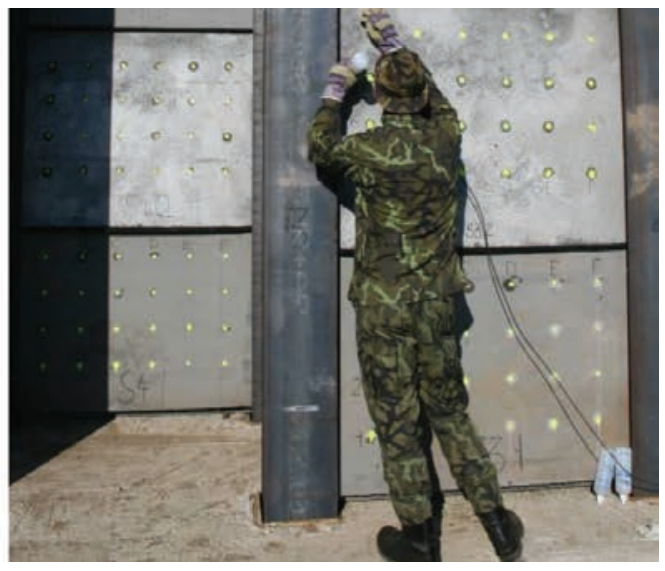

Fig. 17. Ultrasonic verification of cracks in the testing slab after loading by TNT explosion [11]. 


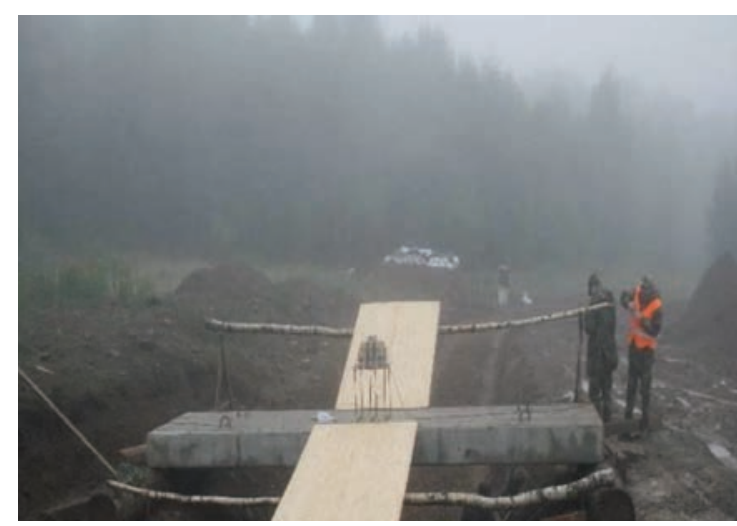

Fig. 18. Field testing in fog [13].

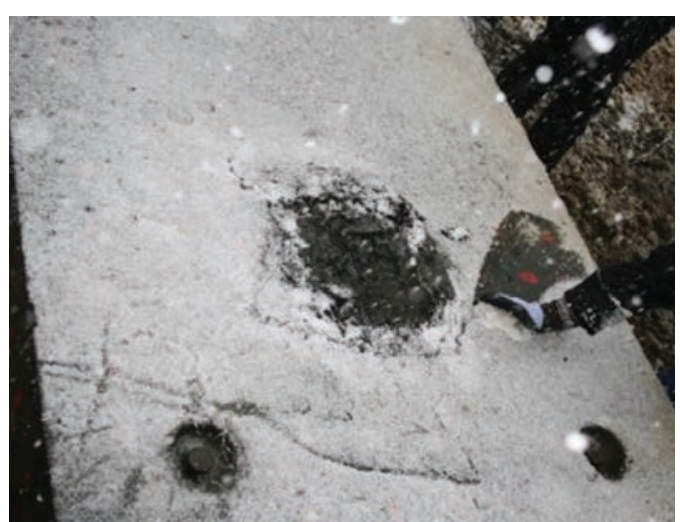

Fig. 19 Field testing in snow [18].

\section{Military Fortification Constructions Diagnostics}

Based on the results of long-term field testing, we are working on creating a methodology for the diagnostics of military fortification structures. It has been proven that ultrasound crack detection in the structure is far from sufficient to assess the current state of the structure and to determine whether it is possible to repeatedly affect the structure. It is necessary to establish a methodology on the basis of which it would be possible to make a qualified judgment as to whether the structure is still able to protect live force.

A structure designed to protect the live force against the effects of a shock wave and projectiles it cannot be diagnosed by such a method as to break the protective structure. For these reasons, non-destructive testing methods should be preferred. Non-destructive testing (NDT) is suitable for the protective structures testing, as the protective properties of the construction are not compromised by sampling. The disadvantage of NDT is relatively complicated evaluation of measurement results. These methods are only partially appropriate for determining whether a military protective structure can withstand additional actions without jeopardize the concealed force. The field testing of structures and materials suitable for the construction of military protective structures is currently underway $[9,10$, $17,19]$.

One of the NDT methods that was used to evaluate the results of field experiments was the Ultrasonic Pulse Velocity (UPV) testing method is based on the measuring of the ultrasound wave velocity in material. The propagation of the ultrasound waves is a function of the properties of the tested material (air $330 \mathrm{~m} \cdot \mathrm{s}^{-1}$, water $1500 \mathrm{~m} \cdot \mathrm{s}^{-1}$, steel $5000-6000 \mathrm{~m} . \mathrm{s}^{-1}$, concrete $3000-5000 \mathrm{~m} \cdot \mathrm{s}^{-1}$ ). The ultrasonic wave is a mechanical wave with frequencies higher than $20 \mathrm{kHz}$, the velocity of which passing through construction materials depends on the physical and mechanical properties of the material as well as on the presence of defects in the structures. The UPV belongs to the group of the non-destructive testing methods. The biggest advantage of those methods is the simplicity of the test performance. The disadvantages include the difficulty in interpreting the results in more complex cases, and the sensitivity of the ultrasound method to the whole range of external factors.

For the ultrasound testing of constructions and materials, ultrasound probes with the operating frequency in the range from $20 \mathrm{kHz}$ to $150 \mathrm{kHz}$ are commonly used. The utilization of other frequencies is not very frequent; however, it is possible. Generally accepted, the resolution and the accuracy of ultrasound measurements are increased with a higher frequency of the ultrasound wave resolution. Nevertheless, high frequencies of ultrasonic waves while passing through the structures are much more strongly attenuated. The recommendations for the UPV [21] of concrete testing with regard to the behavior of the ultrasonic pulse described above, are based on the Czech technical standard ČSN 731371 [22]:

- For a short measuring base (up to $50 \mathrm{~mm}$ ), it is appropriate to use a probe with a high frequency of 60 to $200 \mathrm{kHz}$.

- For a long measuring base (from 1 meter to 15 meters), it is appropriate to use a probe with a low operating frequency of 10 to $40 \mathrm{kHz}$.

- $\quad$ For most of the cases it is appropriate to use a probe with an operating frequency of 40 to $60 \mathrm{kHz}$.

It is necessary to draw attention to the fact that the applicability of a certain frequency probe for a specific case of measurement is given not only by the length of the measuring base, but also by other factors, such as the size of the defect or inhomogeneity, the type of material or the device power.

Basically, there are two principal ways to test the properties of the structures or materials by ultrasound. The first of them is to measure the velocity of ultrasound wave in the tested material. This test detects the physical and mechanical characteristics of the tested material and its potential defects. The second way is the Ultrasonic Pulse Echo 
Method. This method captures reflections of the ultrasonic signal from inhomogeneity, defect or a foreign body in the structure [20].

The ultrasonic pulse velocity method is based on the measurement of the transit time of pulses of ultrasonic waves through the material. The propagation velocity of ultrasonic waves $v_{U Z}$ can be very easily calculate with the known length of measuring base $L$. This velocity is dependent on the quality of the examined material.

The essence of this method is the repeated transmission of ultrasound pulses into the test material. After the pulses pass through the line $L$ whose value is known, they are detected by the sensor. The passage time of ultrasound waves is measured. The pulsed ultrasound wave propagation velocity $v_{U Z}\left[\mathrm{~m} . \mathrm{s}^{-1}\right]$ then can be expressed from the equation:

$$
v_{U Z}=\frac{\mathrm{L}}{\mathrm{t}}
$$

where: $L$ - distance measurement $[\mathrm{m}] ; t$ - arrival time of the reflected energy [s].

This velocity depends on the material type and properties. The pulse ultrasound velocity is higher in quality concrete, whereas in concrete of lower quality is lower (see Fig. 20).

This method is mainly used to detect the quality of the test material or its physical and mechanical characteristics. These characteristics are determined by using the propagation speed of the ultrasonic waves.

For example, pulse velocity can determine:

The material characteristics (dynamic modulus of elasticity, compressive strength, density, distortion (degradation)) or presence of cracks (discontinuities).

For the testing of protective structures, the UPV method was chosen. This method is suitable for assessing the quality of the material and for recognizing the changes that occur after the slabs acting by TNT explosion. See Fig. 21. Before ultrasound testing, a measuring network was marked on each slab, see Fig 7, 8 and 10.
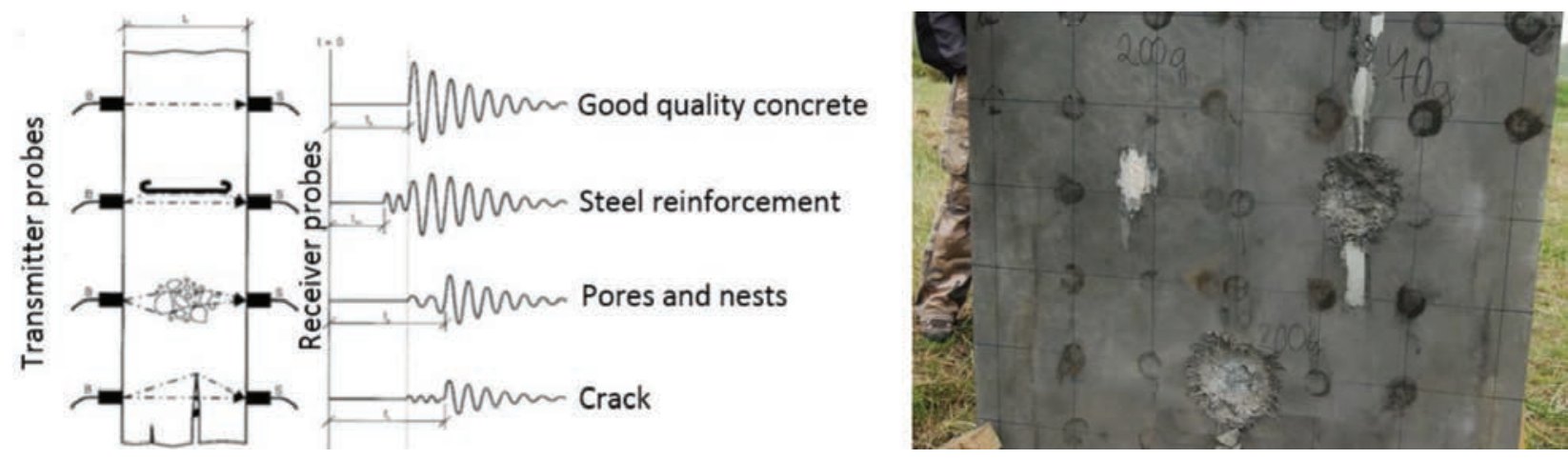

Fig. 20. The influence of the concrete quality on the ultrasound waves velocity of propagation and pulse shape [23].

Fig. 21. Testing slab made of the UHPFRC after triple action of $70 \mathrm{~g}, 200 \mathrm{~g}$ and $200 \mathrm{~g}$ plastic explosives P1 Np 10 [24].

The UPV method was used for cracks detection of the testing slab made of the UHPFRC it was only $100 \mathrm{~mm}$ thick. The Fig. 21 shows the testing slab after triple load of $70 \mathrm{~g}, 200 \mathrm{~g}$ and $200 \mathrm{~g}$ of plastic explosives P1 Np 10 . The Fig. 22 and Fig. 23 show the result of the examination by the ultrasound of the testing slab before and after explosion of the Pl NP 10. The measured values of the ultrasound velocity were taken at every square grid point of the testing slab. To illustrate the propagation of the ultrasound velocity in individual points of the testing slab, the program for creation of isovels named 3D Filed Pro 64 bit was used. This allows visual comparison of results before and after explosion.

The test slab was produced in an accredited building laboratory of the Czech Technical University in Prague. Mixing technology is an integral part of UHPFRC manufacturing process. Before testing, the slab was provided with a square grid on both, reverse and facing sides. On each slab side, 49 points were drowned. See Fig. 21. 


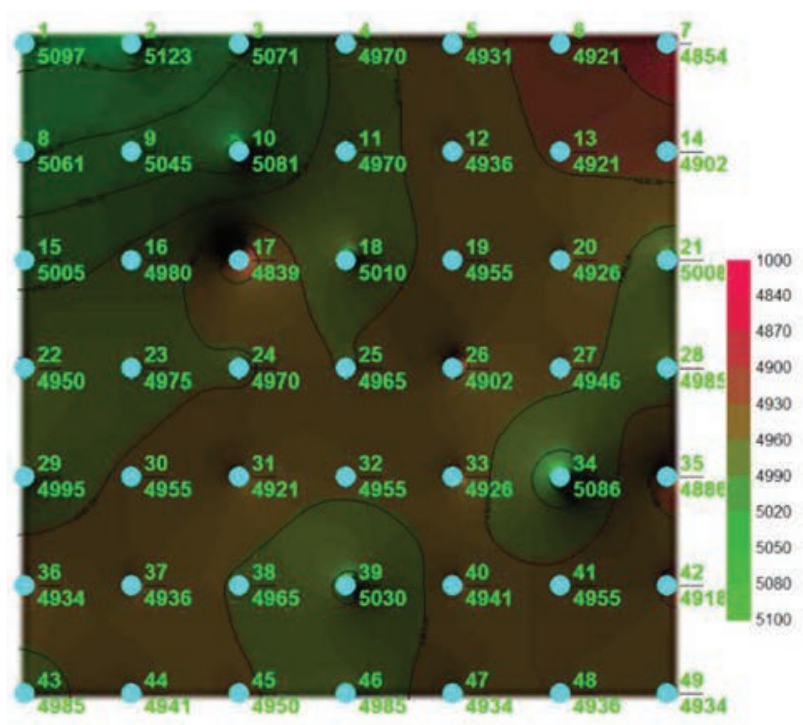

Fig. 22. Isovels distribution the UHPFRC tested slab before loading by explosion of the plastic explosives $\mathrm{Pl}$ Np 10 [24].

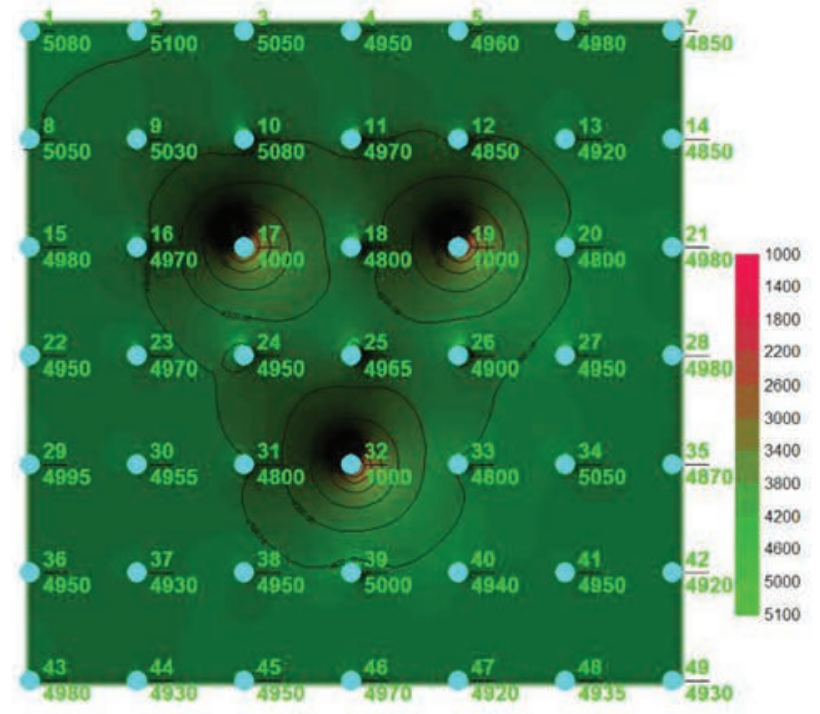

Fig. 23. Isovels distribution the UHPFRC tested slab after loading by explosion of the plastic explosives P1 Np 10 [24].

The result of the triple UHPFRC concrete slab load test is shown in Fig. 23. In three consecutive tests, the tested slab was not punctured, and its structure was changed only within $100 \mathrm{~mm}$ of the center of the load.

\section{Conclusions}

The requirements for military fortification construction are specific regarding the actions that these structures have to carry. The assessment of the condition of these structures is crucial to the Commander's decision as to whether the structure can serve its purpose.

Based on the results of long-term field testing, we are working on creating a methodology for the diagnostics of military fortification structures. It has been proven that ultrasound crack detection in the structure is far from enough to assess the current state of the structure and to determine whether it is possible to load the structure repeatedly. It is necessary to establish a methodology based on which it would be possible to make a qualified judgment as to whether the structure is still able to protect live force.

There is a sophisticated methodology for assessing the condition of structures that is used by the professional public. However, this methodology is designed to assess the condition of structures that are loaded and used in the usual way. Outputs of structures diagnostics are used to decide whether to demolish or reconstruct the structure. Again, most of the diagnostics are followed by reconstruction or construction works. Considering the specific accidental actions, it is necessary to use diagnostic procedures other than conventional constructions, especially regarding the impossibility of breaking the structure by removing the specimen. It is necessary to evaluate the structure for a different type of action than usual. For these reasons, it is possible to use destructive or semi-destructive diagnostics methods. This method also depends on type of the fortification structure and its connection with subsoil [26]. Fortification structures are currently being built as aboveground structures, but if they were constructed as ground structures or were connected to an underground infrastructure, then the impact of pressure wave propagation through the soil would have to be assessed.

In addition, it is necessary to realize that fortification structures are not constructed of the concrete and the reinforced concrete but can be erected or additionally reinforced with earth bodies. This raises the need to extend the method of slope stability evaluation [25].

A structure designed to protect the live force against the effects of a shock wave and projectiles it cannot be diagnosed by such a method as to break the protective structure. For these reasons, non-destructive testing methods should be preferred. The NDT is suitable for the protective structures testing, as the protective properties of the construction are not compromised by sampling. The disadvantage of NDT is relatively complicated evaluation of measurement results. These methods are only partially appropriate for determining whether a military protective structure can withstand additional loads without jeopardize the concealed force. The field testing of structures and materials suitable for the construction of military protective structures is currently underway $[10,11,18,19,20]$.

Although field experimentation is important for knowing the behavior of materials and structures under 
explosive loading, the goal is to develop a procedure for assessing the status of a fortification structure and estimating the level of acceptable risk. The problem of such an evaluation is the uniqueness of each fortification structure. Even if a structure of a similar type to the one that needs to be evaluated is tested. The structures will never be identical. It is never possible to say with certainty that the parameters of both constructions are the same. Particularly in the case of non-homogeneous materials such as concrete, reinforced concrete and, in particular, reinforced concrete, it is necessary to have an NDT material quality control tool [27].

\section{Acknowledgements}

The work presented in this article has been supported by the Czech Republic Ministry of Defence - K 201 Department development program "Development of technologies in the field of weapon construction, ammunition, armament equipment, material engineering and military infrastructure".

\section{References}

1. Maňas P. The Protection of Critical Infrastructure Objects - Technical Principles. In: Durability of Critical Infrastructure, Monitoring and Testing. Singapore: Springer Singapore, 2017, p. 239-248. ISBN 978-981-103246-2.

2. Jung, K., Sýkora, M., Holický M., Marková, J., Maňas, P., Vintr, Z. and Kroupa, L. Safety and risk assessment of road bridges and tunnels. Praha: Czech Technology - Publishing House ČVUT, 2018. ISBN 97880-01-06516-7.

3. Coufal, D., Maňas, P., Benda, M., Sobotka, J. Military Engineering Support in Operation Inherent Resolve. In: 2019 International Conference on Military Technologies (ICMT). Brno: IEEE, 2019, p. 5. ISBN 978-1-72814593-8.

4. Leitner, B., Lusková, M. Quantified Probability Estimation of Traffic Congestion as Source of Societal Risks In: Transport Means 2018. Kaunas: Kaunas University of Technology, 2018, p. 118 123. ISSN 1822 296X.

5. Rolc, S., Křest’an, J., Kopkáně, D., Štoller, J., Maňas, P. Research of Prospective Materials for Military Protective Structures. Applied Mechanics and Materials, 2015, 796 (October 2015), 35-42. ISSN 1660-9336.

6. NATO Standardization Agency. ATP-3.12.1.8 Test Procedures and Classification of the Effects of Weapons on Structures. Brussel, Belgium, 2016.

7. NATO Standardization Agency. STANAG 2280 Design threat levels and handover procedures for temporary protective structures. Brussel, Belgian, 2008.

8. Štoller, J. Utilization of steel fiber reinforced concrete for protective structures. $\mathrm{PhD}$ thesis in the field of "Military construction ". Brno: University of Defence - Faculty of Military Technology - Department of Engineer Technology. 2005. 254 p.

9. Štoller, J., Dubec, B. Design and Assessment of Shape of Protective Structure by Usage of CFD Software Environment Ansys Fluent. In: Durability of Critical Infrastructure, Monitoring and Testing - Lecture Notes in Mechanical Engineering. SINGAPORE: SPRINGER-VERLAG SINGAPORE PTE LTD, SINGAPORE, 2017, p. 200-210. ISSN 2195-4356. ISBN 978-981-10-3246-2.

10. Śtoller, J., Dubec, B. Assessment of Protective Structures on the Basis of Their Acceleration Caused by Blast Wave. In: Durability of Critical Infrastructure, Monitoring and Testing - Lecture Notes in Mechanical Engineering. SINGAPORE: SPRINGER-VERLAG SINGAPORE PTE LTD, SINGAPORE, 2017, p. 8-16. ISSN 2195-4356. ISBN 978-981-10-3246-2.

11. Hejmal, Z., Maňas, P., Štoller, J. Measurement and numerical simulation of the effects of an explosion on HPFRC slab. In: Proceedings of 20th International Scientific Conference Transport Means 2016, Part III. Kaunas, Lithuania: Kaunas University of Technology, 2016, p. 881-884. ISSN 1822-296X.

12. Zezulová, E., Štoller, J. Use of Ultrasound - The ultrasonic pulse velocity method for the diagnosis of protective structures after the load of TNT explosion. In: Conference Proceedings of ICMT'17. Piscataway, NJ 08854-4141 USA: Institute of Electrical and Electronics Engineers Inc, 2017, p. 230-235. ISBN 978-1-5386-1988-9.

13. Zezulová, E., Štoller, J. The Field Testing of High Performance Fiber Reinforced Concrete Slabs under the TNT Load Explosion together with the Analytical Solution and the Numerical Modelling of those Tests Results. In: ICMT 2015 INTERNATIONAL CONFERENCE ON MILITARY TECHNOLOGIES. Brno: University of Defence, 2015, p. 211-218. ISBN 978-80-7231-976-3.

14. ČSN EN 12390-1. Testing of the hardened concrete: Shape, dimensions and other requirements for test specimens and molds. Prague: Czech Standardization Institute, 2001. 12 p.

15. ČSN EN 12390-2. Testing of the hardened concrete: Production and treatment of test specimens for strength tests. Prague: Czech Standardization Institute, 2001. 8 p. 
16. Štoller, J., Zezulová, E., Foglar, M. Non-Destructive Examination of Cement Based Materials before and after Explosion Tests. Applied Mechanics and Materials, 2015, 796(October 2015), 125-136. ISSN 1660-9336.

17. Trtík, T., Chylík, R, Fládr, J., Štoller, J., Broukalová, I. Methods of lighting of concrete structures for highspeed camera measurement. In: IOP Conference Series: Materials Science and Engineering. Praha: Institute of Physics Publishing, 2019, p. 1-10. ISSN 17578981.

18. Fládr, J., Šeps, K., Chylík, R., Štoller, J., Trtík, T. Blast resistance of multi-layered concrete slabs. In: IOP Conference Series: Materials Science and Engineering. Praha: Institute of Physics Publishing, 2019, p. 1-8. ISSN 17578981.

19. Komárková, T., Laník, J., Topolar, L, Štoller, J., Stoniš, P. Experimental assessment of steel fibre reinforced concretes with different concentrations of fibres. In: IOP Conference Series: Materials Science and Engineering. Praha: IOP Publishing, 2018, p. 1-6. ISSN 17578981.

20. Hobst, L.; Adámek, J.; Cikrle, P.; Schmid, P.; Diagnostics of constructions. Brno University of Technology, Brno, 2005.

21. Czech technical standard ČSN EN 12504- 4. Testing of concrete - Part 4: Determination of ultrasonic pulse velocity. Prague: Czech Office for Standards, Metrology and Testing, 2005.

22. Czech technical standard Czech technical standard ČSN 73 1371. Ultrasound pulse method of concrete testing. Prague: ÚNM Publishing, 1982. 20 pages.

23. Anton, O. Fundamentals of testing. Teaching texts of universities. Brno: CERM s.r.o Brno, 2002. ISBN: 80-2142079- 0 .

24. Zezulová, E., Štoller, J. Field Tests of Cementitious Materials Suitable for Force Protection and Critical Infrastructure Protection. In: Proceedings of International Conference on Military Technologies Brno 2019. Brno: University of Defence in Brno, 2019, p. 892. ISBN 978-80-213-2955-3.

25. Dudchenko, O.L., Shibaev, I.A., Ivanov, P.N., Kravcov, A.N. Development of geotechnical protective measures for strengthening a slope prone to landslide hazards. In Proceedings of the XV International Forum-Contest of Students and Young Researchers under the auspices of UNESCO. St. Petersburg Mining University, Russia, 1317 May 2019. p. 147: ISBN 978-0-367-02743-8.

26. Kravcov, A. N., Svoboda, P., Pospichal, V. Definition of the load against underground structures due to shock wave propagation in rocks. In: Conference Proceedings of ICMT'17. Piscataway, NJ 08854-4141 USA: Institute of Electrical and Electronics Engineers Inc, 2017, p. 230-235. ISBN 978-1-5386-1988-9.

27. Komárková, T., Anton, O., Stoniš, P., Dubec, B. NDT method for the assessment of homogeneity of steel fibre reinforced concrete. In: Proceedings of International Conference on Military Technologies Brno 2019. Brno: University of Defence in Brno, 2019, p. 635. ISBN 978-80-213-2955-3. 